\title{
KINETIC MEASUREMENTS ON ELEMENTARY FOSSIL FUEL COMBUSTION REACTIONS OVER WDE TEMPERATURE RANGES
}

Progress Report

For the Period December 1, 1990 - November 30, 1991

\section{Arthur Fontijn}

High-Temperature Reaction Kinetics Laboratory

The Isermann Department of Chemical Engineering Rensselaer Polytechnic Institute

Troy, New York 12180-3590

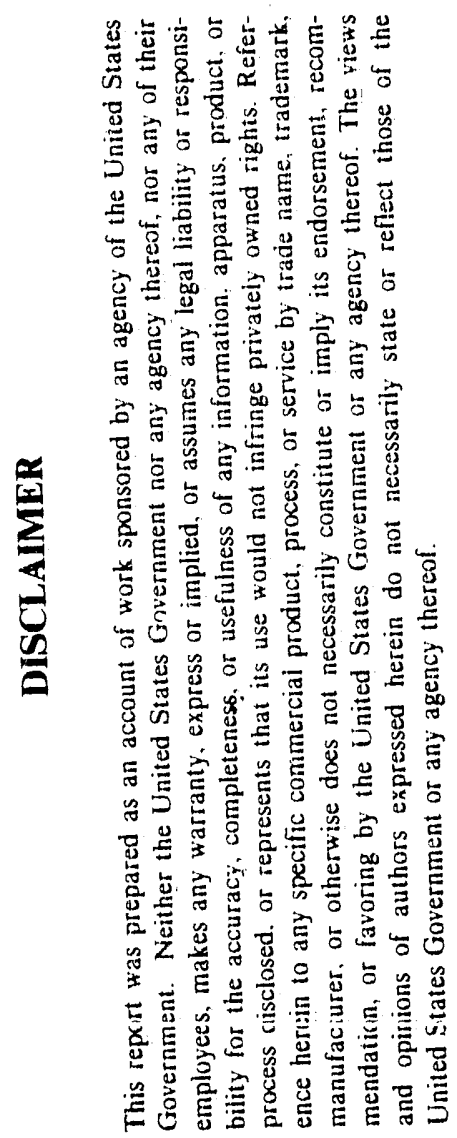

January 1992

Prepared for

THE U.S. DEPARTMENT OF ENERGY

AGREEMENT NO. DE-FG02-84ER 13224 


\section{INTRODUCTION AYD WETHOD}

The goals of this work are to provide accurate data on the temperature dependence of the kinetics of elementary combustion reactions (i) for use by combustion modelers, and (ii) to gain a better fundamental understanding of, and hence predictive ability for, the chemistry involved. Experimental measurements are made using the pseudo-static HTP (high-temperature photochemistry) technique. This approach allows observations on single reactions in the 300 to $1800 \mathrm{~K}$ temperature range to be made. Typical total (bath gas) pressures are in the 100 to 1000 mbar range: Ground-state $O$ and $H$ atoms are produced by flash or excimer laser photolysis of suitable precursors $\left(\mathrm{O}_{2}, \mathrm{CO}_{2}, \mathrm{SO}_{2}, \mathrm{NH}_{3}\right)$. The relative atom concentrations are monitured by resonance fluorescence pumped by a cw microwave discharge flow lamp. The molecular reactant-in-excess is introduced through a cooled inlet. Adequate time for mixing, 0.1 to $10 \mathrm{~s}$, between this inlet and the photolysis/observation zone is achieved by using slow flows (typically less than $20 \mathrm{~cm} \mathrm{~s}^{-1}$ ).

\section{PROGRESS}

In the reporting period our results on the reactions of $O$ atoms with benzente and 1-butene were prepared for publication and have since appeared in the Journal of Physical Chemistry. 1.2 Experiments on the reactions of $O$ atoms with isobutene and with cis and trans 2-butene, as well as those of $\mathrm{H}$ atoms with $\mathrm{HCl}$ have been completed; the results are being prepared for publication. Work on the O-atom reaction with l-butadiene has commenced.

\section{O-Atom Reactions with the Four Isomeric Butenes}

Figure 1 summarizes our results on these reactions. While the 1-butene results have already been published, 2 we will repeat some of our observations on that reaction here as the comparison between the butenes is a major goal of these studies. The following empirical best fits have been obtained. all in $\mathrm{cm}^{3}$ molecule-1 $\mathrm{s}^{-1}$ : 


\section{$\mathbf{T}, \mathbf{K}$}

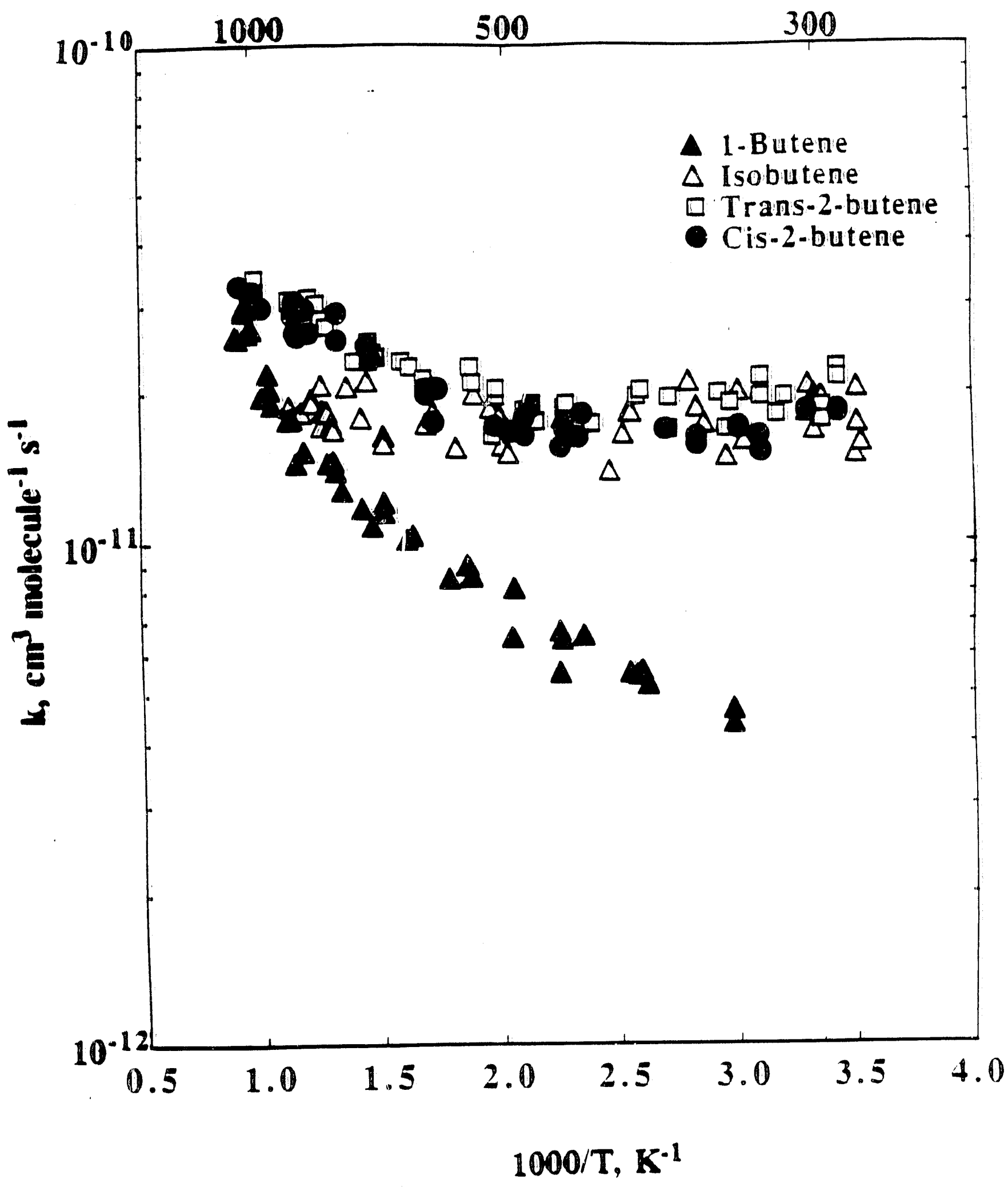

Figure 1

The Present Measurements on the O-Atom Reactions with the Four Isomeric Butenes. 
$0+1-\mathrm{C}_{4} \mathrm{H}_{8}: \mathrm{k}(3.40-1110 \mathrm{~K})=2.71 \times 10.11 \exp (-02+\mathrm{K} / \mathrm{T})+2.37 \times 10^{-9} \exp (-5057 \mathrm{~K} / \mathrm{T})$

$\mathrm{O}+\mathrm{iso}^{\mathrm{s}} \cdot \mathrm{C}_{4} \mathrm{H}_{8}: \mathrm{k}(284-886 \mathrm{~K})=1.78 \times 10-11 \mathrm{exp}(-36 \mathrm{~K} / \mathrm{T})$

$\mathrm{O}+\operatorname{cis}-2-\mathrm{C}_{4} \mathrm{H}_{8}: \mathrm{k}(292-1086 \mathrm{~K})=2.37 \times 10^{-17}(\mathrm{~T} / \mathrm{K})^{1.94} \exp (716 \mathrm{~K} / \mathrm{T})$

$0+\operatorname{tans}-2-\mathrm{C}_{4} \mathrm{H}_{8}: \mathrm{k}(292-1022 \mathrm{~K})=5.24 \times 10 \cdot 16 \cdot(\mathrm{T} / \mathrm{K}) 1.51 \exp (577 \mathrm{~K} / \mathrm{T})$

with accuracy limits of about $\pm 27 \%$. These are in good agreement with previously reported low temperature $(T<500 \mathrm{~K}$ ) data $3-6$ as well as with the best fit expressions for the four reactions in the 260-860 $\mathrm{K}$ range given in an abstract by Perry. 7 In agreement with Perry, we find that the 1-butene reaction differs markedly from the other three in that it has a much lower rate coefficient at low temperatures and shows a very strong upward curvature in its Arrhenius plot. In the following we briefly provide an explanation for these differences.

At low temperatures the reactions proceed by electrophilic addition of 0 atoms to the double bond. 4 However, H-atom abstraction leading to OH has been observed at higher temperatures for reaction (1) in a laser-induced fluorescence, LIF, study" and for reactions (1) through (3) in a mass spectrometer study. ${ }^{9}$ To describe the addition channels we have followed the transition state theory procedure of singleton and Cvetanovic. ${ }^{4}$ This approach bails to reproduce the strong curvarure of reaction (1). The rate coefficients for abstraction of primary, secondary and tertiary $H$ atoms by oxygen atoms have been estimated by Huie and Herron 10 to be $8.3 \times 10^{-12} \exp (-2900 \mathrm{~K} / \mathrm{T}), 2.2 \times 10^{-11} \exp (-2250 \mathrm{~K} / \mathrm{T})$ and $2.7 \times 10^{-11} \exp (-1650 \mathrm{~K} / \mathrm{T})$ $\mathrm{cm}^{3}$ molecule-1 $\mathrm{s}^{-1}$, respectively. The addition of such terms to those for addition results in good agreement with the experimental results for the 0 + 1-butene reaction.2 For the three other reactions, the relatively high rate coetficients for the addition channel obscure the small contribution of the abstraction channel at the presently investigated temperatures, hence the slight curvature observed in their Arrbenius plots. 
The difference in the values of the rate coefficients below 50 (o) $K$ requires an explanation based on the ditference in the addition channels. Consideration of the electron donating effects of the alkyl groups to the double bonds clarifies the observations in that the activation energy is influenced by the inductive and hyperconjugative effects of alkyl groups artached to the double bond. 12 In isobutent. trans-2-butene, and cis-2-butene two methyl groups are attached to the double bond. while in l-butente an ethyl group is attached to that bond. The effect of these structural differences is an increase in the negative character of the double bonds in ischutene, trans-2butene and cis-2-botene, resulting in lower activation energies for reactions (2), (3), and (4). Since the four reactions have about the same preexponential factors, the rate coefficients for the l-butene reaction are lower.

$$
\mathrm{H}+\mathrm{HCl} \rightarrow \mathrm{H}_{2}+\mathrm{Cl}
$$

Baulch, et al. in their evaluation 13 considered the direct rate coefficient masurements on this reaction to be too scattered and unreliable to allow a recommendation. Instead they made a recommendation based on the reverse reaction. The data by Ambridge, et ad for the forwand reaction. appeared 3 to be the most reliable. It may be seen in Fig. 2 that our results are in good agreement with both of these references. It is interesting to note, ctf. Fig. 2, that the only previous measurements above $520 \mathrm{~K}$ on this reaction, i.e., those of Steiner and Rideal. as recalculated by Benson, 15 are in good agreement with our measurements as well. The Baulch recommendation does not extend above $620 \mathrm{~K}$, since that is the maximum temperature for which the reverse reaction has been measured. We thus have nearl: doubled the temperature range for which $k(T)$ for the forward reaction now may be considered to be reliably known. We also plan to extend the measurements on the reverse reaction to higher temperatures. 
T, $\mathbf{K}$

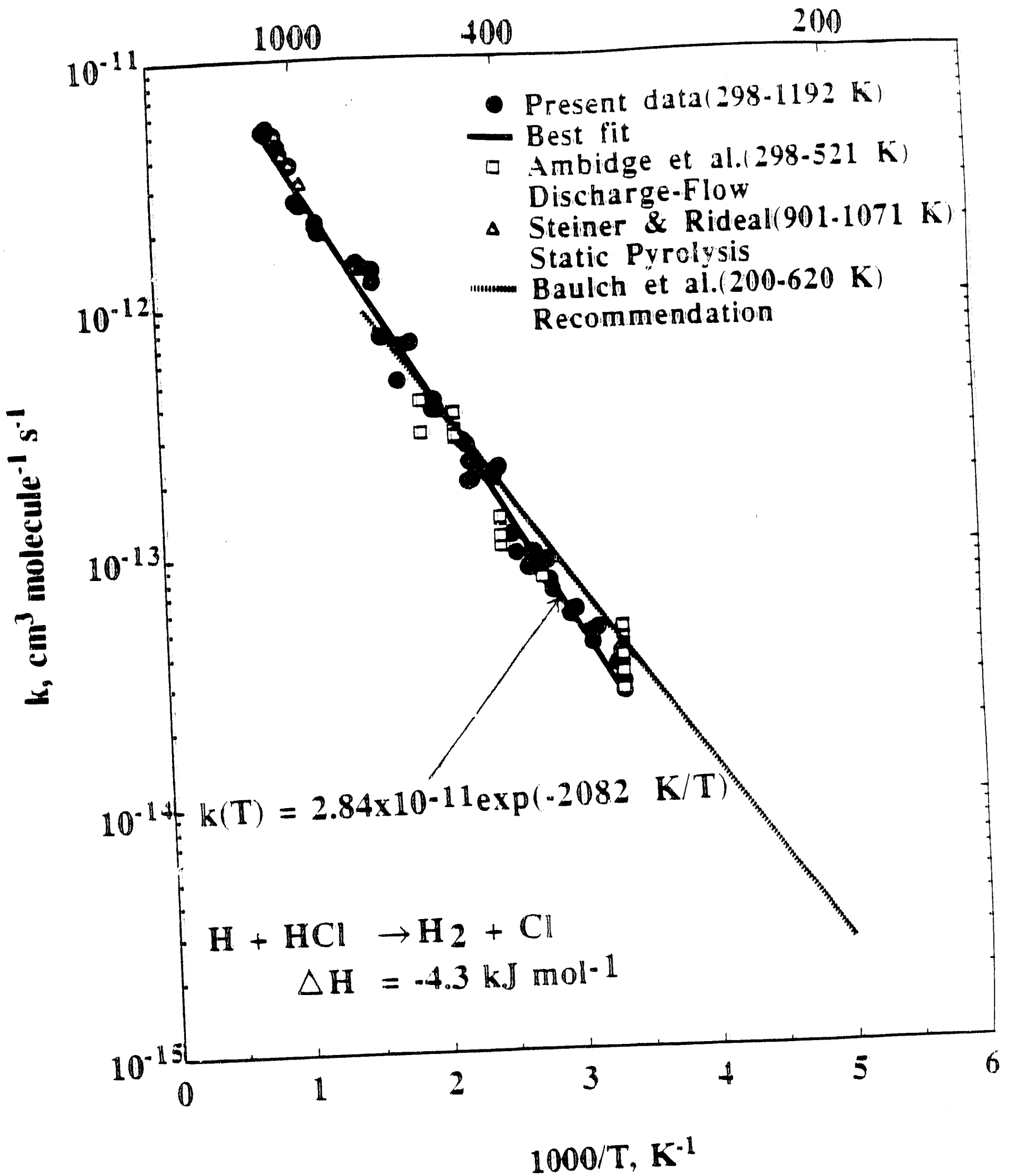

Figure 2 


\section{The O-Atom 1,3-butadiene Reaction}

Our indial studies of this reaction showed nonexponential decaly lo Those experiments were made using tiash lamp phorolysis of 02 and $C O 2$ in the deser vacum ultraviolet. We now have commenced work on this reaction using the lys mm laser photolysis of $\mathrm{SO}_{2}$ as the O-atom source. The tirst indications are that this approach is successiful.

\section{REFERENCES}

1. T. Ko, G.Y. Adusei and A. Fontign, "Kinetics of the O(3P) + $\mathrm{C}_{0} \mathrm{H}_{\text {og }}$. Reaction over a Wide Temperature Range", J. Phys. Chem. 15,8745 (199'l).

2. T. Ko, G.Y. Adusei and A. Fontijn, "Kinetics of the Reactions between $O(3 \mathrm{P})$ and $1-$ Butene from 335 to 11 llo K", I. Phys. Chem. 95, 9360. (1991).

3. R.E. Huie, J.T. Herton and D.D. Davis. "Absolute rate Constants tor the Addition and Abstraction Reartions of Atomic Oxygen with 1-Butene over the Temperarure Range 19(0)+91 K"., I. Phys. Chem. 76, 331181972).

4. D.L. Singleton and R.J. Cvetanovic. "Temperature Dependence of the Reactions of Oxygen Atoms with Oletins", I. Am. Chem. Soc. 98, 6812(1976).

5. R. Atkinson and J.Y. Pitts, Ir., "Absolute Rate Constants for the Reaction of O(3F). Acoms with a Series of Otetins over the Temperature Range $298-439 \mathrm{~K} "$. I. Cirm. Phys. (67, 38(1977).

6. R. Browarzik and F. Stuhl. "Temperature Dependence of the Rate Constants for the Reactions of Oxygen Aroms with Ethene. Propene, and 1-Butene", J. Phys. Chem. $88, \quad 6(0)(0)+(1984)$.

7. R.A. Perry, "Kinetics of the Reaction of $O$ atoms with Oletins over the Temperarure Range 260-860 Kr using Laser Phorolysis-Chemiluminescence", Abstracts of Papers for the 188 th American Chemical Society National Meting. Philadelphia, Pennsylvania, August, 1984.

8. K. Kleinermanns and A.C. Luntz. "The Chemical Dynamics gf Hydrogen Atom Abstraction trom Unsaturated Hydrocarbons by O(3P)", I. Chem. Phys., 77 , $3533(1982)$.

9. B. Blumenberg, K. Hovermann and R. Sievert. "Primary Products in the Reactions of Oxygen with Simple and Substituted Hydrocarbons". Sixteenth Symposium(International) on Combustion, p.84t. The Combustion Institute, 1977. 
10. R. E. Huie and J. T. Herton, "Reactions of Atomic Oxygen Or ipl with Orgadnc Compounds", Prog. Redet. Kin. $1+1975)$.

11. P. Sykes, A Guidebook to Mechanism in Organic Chemistry, Brd. ed. Longmans, Green \& Co. Ltd., 1970), pp. 20, 24, and 159.

12. C.A. Amington and D.J. Cox, "Arrthenius Parameters for the Reaction of Oxygen Atoms, O(3P), with Propyne", I. Phys Chem. 79, 2584 (1975).

13. D.L. Baulch, J. Duxbury, S.J. Ginant, and D.C. Montague, J. Phys. Chem. Reft. Data, 10. (1981), Suppl! 1, p: 161-1 fif.

14. P.F. Ambidge, J.N. Bradley and D.A. Whytock, J.C.S. Faractay I, 72, 2143 (1976):

15. S.W. Benson, F.R. Cruicksthank and R. Shaw, Int. I. Chem. Kin. 1, 29 (1969):

16. K. Mahmud, "Kinetic Studies of the Reactions of Oxygen and Hydrogen Anoms with Some Hydrocarbon Molecules over Wide Temperature Ranges", Ph.D. Thesis, Rensselaer Polytechnic Institute, 1988 . 

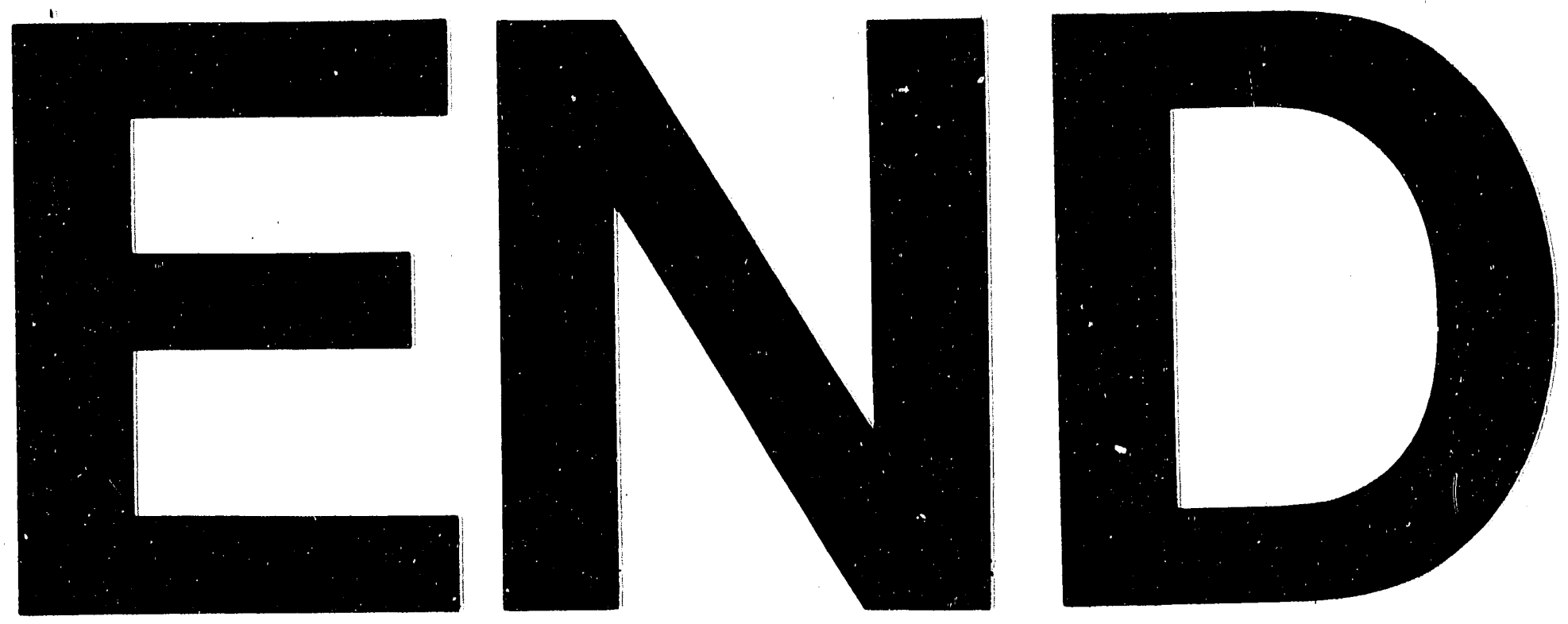

$$
\text { te }
$$
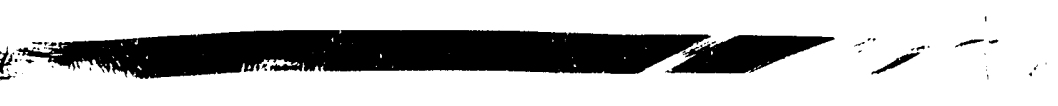

,
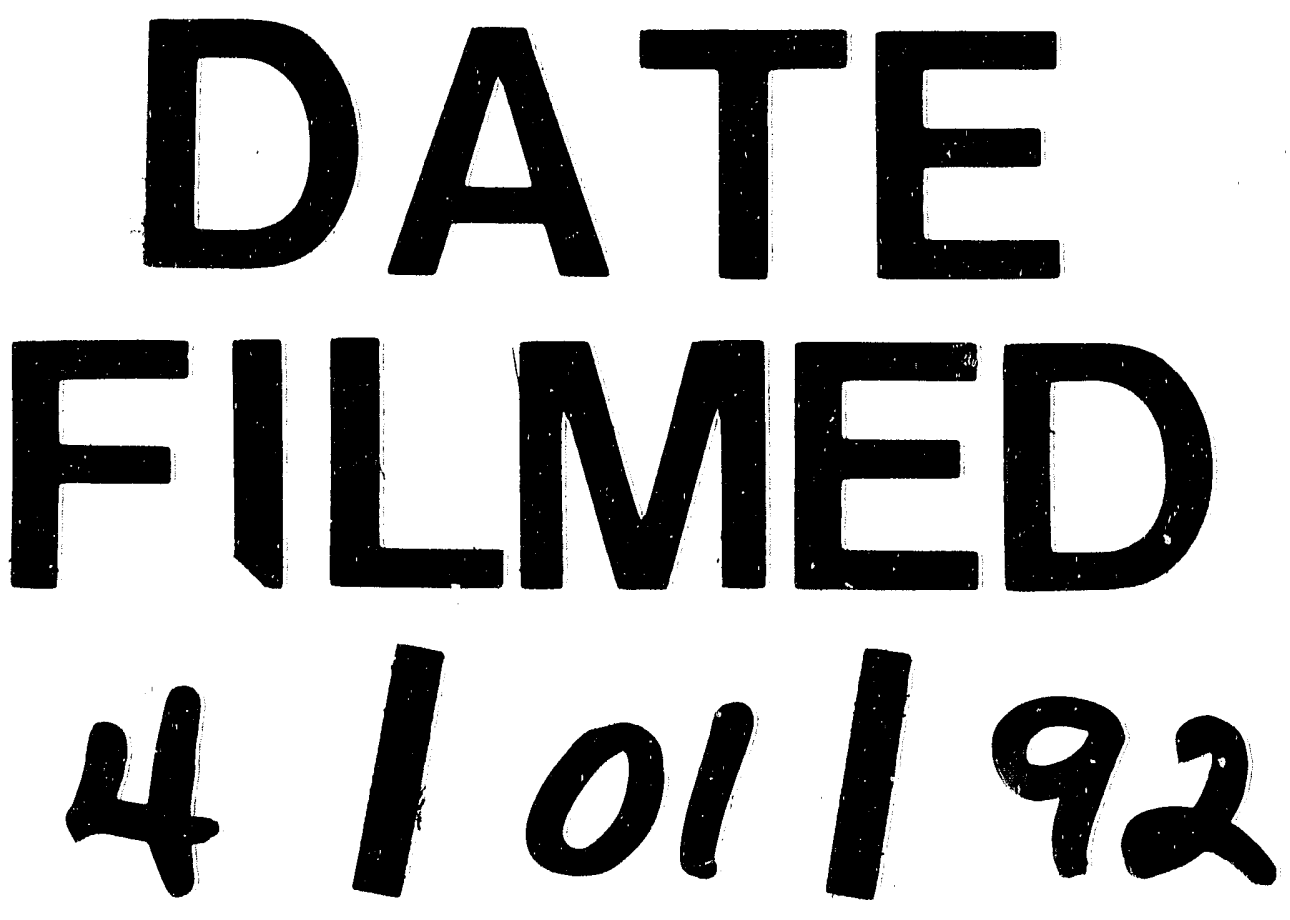

$I$ 
